\title{
A Review of Stock Return Synchronicity
}

\author{
Ningning Pan ${ }^{1, a}$ Hongquan Zhu ${ }^{1 \text {, a }}$ \\ ${ }^{1}$ School of Economics and Management, Southwest Jiaotong University, Chengdu, \\ 610031,PR,China \\ apnn1986@163.com
}

Keywords: stock return synchronicity, firm-specific information, noise

\begin{abstract}
Stock return synchronicity, or comovement, measures to what extent the individual stock returns would comove with market returns. In empirical analyses, stock return synchronicity is typically measured by the R-square derived from the market model. According to the market efficiency theory, an individual firm's stock price reflect market-level, industry-level, and firm-specific information. King (1966) shows that stock prices covary with market and industry returns, but Roll (1988) finds that the market and industry level information can only explain a small part of the individual stock returns' movement in US market, with market model R2 around 20\% 30\%. Roll (1988) concludes that the residual movements could be explained either by private information or occasional frenzy unrelated to specific information. Following insights by Roll (1988), stock return synchronicity has become a hot topic of financial research. We review and summarize the existing literature from the following three aspects.
\end{abstract}

\section{Stock return synchronicity and firm-specific information}

Following the comment of Roll (1988) that low R-squares seem "to imply the existence of either private information or else occasional frenzy unrelated to concrete information," the link between stock return synchronicity and firm-specific information has been extensively explored and has triggered much debate. Two dramatically different views on the information implication of the stock return synchronicity have emerged.

One school of research support the information-based explanation of stock return synchronicity. Morck et al. (2000) find that stock return synchronicity is higher in countries with weaker protection for private property rights. They argue that weak property rights discourage informed arbitrage, leading to a slower incorporation of firm-specific information into stock prices and larger stock return comovement across firms. In a firm-level study within the US market, Durnev et al. (2003) examine the relation between stock return synchronicity and the accounting measures of stock price informativeness. They find that greater firm-specific stock return variation (or lower $\mathrm{R}$-square) is associated with more informative stock price, which price informativeness is defined as how much information stock prices contain about future earnings. Since these findings, Jin and Myers (2006), Piotroski and Roulstone (2004), Ferreira and Laux (2007), Hutton, Marcus, and Tehranian (2009) provide indirect evidence that supports the information-based explanation of stock return synchronicity. Gul et al.(2010) confirm that the stock return synchronicity is higher if there is less firm-specific information in the market and provides evidence on the validity of R-square as an information measurement in China.

Two recent papers provide views support the information-based explanation of stock return synchronicity. Bae et al. (2013) use a firm' s geographic proximity to its investors as a proxy for private information and provide additional evidence supporting the view that higher firm-specific return variation (lower stock return synchronicity) is indicative of more informative stock prices. Dang et al. (2014) construct a direct measure of firm-specific information using a unique global news dataset, and provide direct evidence that the availability of firm-specific information is an important factor driving stock return synchronicity.

Another school of research maintains the opposite view, suggests that low stock return synchronicity is associated with stock prices that contain less firm-specific information because of 
limits to arbitrage or noise.

West (1988) provides a theoretical model in which low R-square is associated with less firm-specific information and more noise in returns. Ashbaugh-Skaife et al. (2006) show that their analyses of six large equity markets provide little support for using firm-specific return variation as a measure of firm-specific information internationally. Their results are contrary to Durnev et al. (2003). Kelly (2007) show that low R-square stocks have a poor information environment: high information costs and greater impediments to informed trade, and he concludes that low stock return synchronicity is not indicative of information. Consistent with Kelly (2007), Teoh et al. (2009) show that high firm-specific return variation is related to poor firm-level information environment, as measured by earnings quality, earnings persistence, and earnings predictability, and have a higher probability of distress. Dasgupta et al. (2010) develop a model that a more transparent information environment can lead to higher stock return synchronicity, and provide empirical support for their theoretical prediction.

Two recent papers have attempted to reconcile the opposing views on stock return synchronicity as a measure of information efficiency. Xing and Anderson (2011) posit that stock price synchronicity can be low in either good or bad firm-specific information environments because stock prices incorporate both public and private information, and they provide evidence supporting an inverse U-shaped relation between synchronicity and public information. Lee and Liu (2011) argue that the relation between price informativeness and firm-specific volatility is a function of firm information environment and so firm-specific return variation develop a theoretical model and empirically document a U-shaped relation between price informativeness and idiosyncratic volatility.

\section{The influencing factors of stock return synchronicity}

Following insights by Roll (1988), a growing body of literature discussed the factors that affect stock return synchronicity, including cross-country analysis and firm-level analysis.

Morck et al. (2000) find the stock return synchronicity is higher in emerging market than developed market due to weaker protection for property rights. Jin and Myers (2006) complement the findings of Morck et al. (2000) and observe that stock return synchronicity is greater in countries with more opaque information environments. They show that a lack of transparency enables insiders to control firm-specific information flows to the public and therefore to absorb some firm-specific variation. Chan and Hameed (2006) find that greater analyst coverage increases cross-country stock price synchronicity, concluding that analysts primarily produce market-level information. Fernandes (2009) investigate the relation between a country's first-time enforcement of insider trading laws and stock price informativeness of 48 countries, find stock prices become more informative after an initial enforcement of insider trading laws, but the positive response of price informativeness to the enforcement of insider trading laws is concentrated in developed markets. Yu (2011) find that firm-specific stock return variation increases with the quality of a firm's corporate governance. and the effect of corporate governance on price non-synchronicity is higher for firms in countries with strong institutional environments.

For firm-level analysis, Piotroski and Roulstone (2004) investigate how different types of market participants influence a firm' s information environment in terms of firm-specific, industry-level, and market-level information, which find that stock return synchronicity is positively associated with analyst forecasting activities, and inversely related to insider trades. Ferreira and Laux (2007) find that idiosyncratic risk is decreasing in a firm' $s$ degree of insulation from takeovers, implies that a tight link between openness to the market for corporate control and openness of private information flow to the market. Hutton et al. (2009) examine firm-level opaqueness and stock return synchronicity and provide evidence that is consistent with the previous findings of an association between opacity and higher stock return synchronicity. Brockman and Yan (2009) find a negative relation between block ownership and stock return synchronicity; but this relation is significant for both inside and outside blockholders, insignificant for blocks controlled by employee stock 
ownership plans (ESOPs). Gul et al. (2011) show that stock prices of firms with gender-diverse boards reflect more firm- specific information, and the relationship is stronger for firms with weak corporate governance suggesting that gender-diverse boards could act as a substitute mechanism for corporate governance that would be otherwise weak.

In cross-country studies of Morck et al. (2000) and Jin \& Myers (2006), China has the very high stock return synchronicity. In the forty sample countries in Morck et al.(2000), the stock return synchronicity of Chinese stock market is ranked as the second high across the full sample; while in Jin \& Myers (2006)' s paper with same country sample but different time period, China has the highest stock return synchronicity. As a result, more and more scholars tend to focus on examining the stock return synchronicity in China.

From the perspective of corporate governance in China, Gul et al.(2010) find the stock return synchronicity is associated with the concentration of firms' ownership structure, foreign shareholders' ownership and audit quality. Their study confirms that the stock return synchronicity is higher if there is less firm-specific information in the market and provides evidence on the validity of R2 as an information measurement in China. Hou et al. (2012) find the share structure reform in China improves the information environment of Chinese listed firms, especially for the firms with high proportion of non-tradable shares. Xu et al. (2013) first confirm the positive relationship between stock return synchronicity and the analysts following in China. Furthermore, by separating the analysts into star analysts and non-star analysts, they find the star analysts can actually reduce the comovement. Ding et al. (2013) find the fund ownership can increase the amount of information that contained in the stock price, but the impact is diminished for state-owned firms.

\section{The economic consequences of stock return synchronicity}

Consistent with the information-based explanation of stock return synchronicity, Wurgler (2000) shows that the efficiency of capital allocation across countries is negatively correlated with stock return synchronicity in domestically traded stock returns. Then many studies show that stock return synchronicity affects the efficiency of capital allocation, corporate governance.

Durnev et al. (2004) showed that firms with higher firm-specific stock return variation are associated with higher quality capital budgeting in that their marginal Tobin' s Qs are closer to one. They argued that the private information in price, as measured by price non-synchronicity, enhances investment efficiency. Chen et al. (2007) find that price non-synchronicity is strongly positively correlated with the sensitivity of investment to price, suggest that stock prices with large content of private information provide managers with more new information, which, in turn, affects managers' investment decisions.

Defond and Hung (2004) find that in countries with strong law enforcement, CEO turnover is more likely to be associated with poor stock returns when stock prices are more informative. This result suggests that stocks with low synchronicity contain more private information about firm performance and hence generate an effect of poor stock returns on CEO turnover decisions. Ferreira et al. (2011) find a negative relation between price informativeness and board independence, suggesting that firms with more informative stock prices have less demanding board structures.

The higher stock return synchronicity can not only impact the efficiency of capital allocation and corporate governance, but also the stable of the capital market. Jin and Myers (2006) find opaque stock with high synchronicity are more likely to crash. Managers conceal the bad news to protect their jobs, however, stock price crashes when accumulated bad news suddenly becomes publicly available. The empirical results of Hutton et al. (2009) also support Jin and Myers' (2006) this prediction.

\section{Summary}

There are three kinds of views on the information implication of stock return synchronicity: 
lower R-square means more firm-specific information, low R-square is associated with less firm-specific information and more noise in returns, an inverse U-shaped relation between synchronicity and price informativeness. At the country-level, researchers have reached a relatively consistent conclusion: stock return synchronicity is higher in emerging market than developed market. Explanations for this phenomenon including stronger property rights, more transparent information environments, enforcement of insider trading laws, better corporate governance in developed markets.

At the firm-level, there is no consistent conclusion. In a latest research, Dang et al. (2014) point that contradictory views on the information implication of stock return synchronicity are likely driven by the manner in which firm-specific information is measured. In their study, they construct a direct measure of firm-specific information, provide evidence support the information-efficiency view that lower price synchronicity is caused by greater capitalization of firm-specific information. There is also a growing body of literature providing evidence that firms' ownership structure, analysts following, block ownership, firm-level opaqueness, gender-diverse boards, corporate governance can affect stock return synchronicity of different firms.

Deep Insight into stock return synchronicity is very important for regulators, managers and investors. As many studies show that higher stock return synchronicity can not only impact the efficiency of capital allocation and corporate governance, but also the stable of the capital market. Our review and summary can help market participants better understand stock return synchronicity.

\section{Reference}

[1] Ashbaugh-Skaife, H., Gassen, J., LaFond, R., 2006. Does stock price synchronicity represent firm-specific information? The international evidence. Working Paper, University of Wisconsin-Madison.

[2] Bae, K. H., Kim, J. M., Ni, Y., 2013. Is Firm-specific Return Variation a Measure of Information Efficiency?. International Review of Finance 13(4), 407-445.

[3] Brockman, P., Yan, X., 2009. Block ownership and firm-specific information. Journal of Banking and Finance 33, 308-316.

[4] Chan, K., Hameed, A., 2006. Stock Price Synchronicity and Analyst Coverage in Emerging Markets. Journal of Financial Economics 80, 115-147.

[5] Chen, Q., Goldstein, I., Wei, J., 2007. Price informativeness and investment sensitivity to stock price. Rev. Financ. Stud. 20, 619 - 650.

[6] Chen, Z., Du, J., Li, D., Ouyang, R., 2013. Does foreign institutional ownership increase return volatility? Evidence from China. Journal of Banking \& Finance 37(2), 660-669.

[7] Dang, L. T., Moshirian, F., Zhang, B., 2014. Commonality in news around the world. Journal of Financial Economics, forthcoming.

[8] Dasgupta, S., Gan, J., Gao, N., 2010. Transparency, price informativeness, and stock return synchronicity: Theory and evidence. Journal of Financial and Quantitative Analysis 45(5), 1189-1220.

[9] DeFond, M., Hung, M., 2004. Investor Protection and Corporate Governance: Evidence from Worldwide CEO Turnover. Journal of Accounting Research 42(2), 269-312

[10]Ding, R., Hou, W., Kuo, J. M., Lee, E., 2013. Fund ownership and stock price informativeness of Chinese listed firms. Journal of Multinational Financial Management 23, 166-185.

[11]Durnev, A., Morck, R., Yeung, B., 2004. Value - enhancing capital budgeting and firm specific stock return variation. The Journal of Finance 59(1), 65-105.

[12]Durnev, A., Morck, R., Yeung, B., Zarowin, P., 2003. Does Greater Firm - Specific Return Variation Mean More or Less Informed Stock Pricing?. Journal of Accounting Research 41(5), 797-836.

[13]Gul F., Kim, J.-B., Qiu, A., 2010. Ownership concentration, foreign shareholding, audit quality 
and stock price synchronicity: Evidence from China. Journal of Financial Economics 95, 425-442

[14]Gul, F. A., Srinidhi, B., Ng, A. C., 2011. Does board gender diversity improve the informativeness of stock prices?. Journal of Accounting and Economics 51(3), 314-338.

[15]Hutton, A., Marcus, A., Tehranian, H., 2009. Opaque financial reports, R2, and crash risk. Journal of Financial Economics 94, 67-86.

[16]Jin, L., Myers, S. , 2006. R2 around the world: new theory and new tests. Journal of Finance 79, 257-292.

[17]Kelly, P. J., 2007. Information efficiency and firm-specific return variation. Working Paper, University of South Florida.

[18]King, B., 1966. Market and industry factors in stock price behavior. Journal of Business 39, 139-190.

[19]Lee, D. W., Liu, M. H., 2011. Does more information in stock price lead to greater or smaller idiosyncratic return volatility?. Journal of Banking \& Finance 35(6), 1563-1580.

[20]Li, K., Morck, R., Yang, F., Yeung, B., 2004. Firm-specific Variation and Openness in Emerging Markets. Review of Economics and Statistics 86, 658-669.

[21]Morck, R., Yeung, B., Yu, W., 2000. The information content of stock markets: why do emerging markets have synchronous stock price movements? Journal of Financial Economics 58, 215-260.

[22]Piotroski, J., Roulstone, B., 2004. The influence of analysts, institutional investors, and insiders on the incorporation of market, industry, and firm-specific information into stock prices. The Accounting Review 79, 1119-1151.

[23]Roll, R., 1988. R2. Journal of Finance 43, 541-566.

[24]Teoh, S. H., Yang, Y., and Zhang, Y., 2007. R-square: noise or firm-specific information? Working Paper, University of California at Irvine.

[25]West, K., 1988. Dividend Innovations and Stock Price Volatility. Econometrica 56, 37-61.

[26]Wurgler, J., 2000. Financial Markets and the Allocation of Capital. Journal of Financial Economics 58, 187-214

[27]Xu, N., Chan, K. C., Jiang, X., Yi, Z., 2013. Do star analysts know more firm-specific information? Evidence from China. Journal of Banking \& Finance 37, 89-102.

[28]Yuan, R. ., Xiao, J. . ., Zou, H., 200 . Mutual funds' ownership and firm performance: evidence from China. Journal of Banking \& Finance 32, 1552-1565. 